\title{
TRENDS IN RESPIRATORY MORBIDITY OF CHILDREN IN RELATION TO THEIR PASSIVE SMOKING EXPOSURE
}

\author{
Lubomír Kukla ${ }^{1}$, Drahoslava Hrubá2, Mojmír Tyrlík ${ }^{3}$ \\ ${ }^{1}$ Department of Preventive and Social Pediatry, Faculty of Medicine, Masaryk University, Brno, Czech Republic \\ ${ }^{2}$ Department of Preventive Medicine, Faculty of Medicine, Masaryk University, Brno, Czech Republic \\ ${ }^{3}$ Department of Psychology, Faculty of Philosophy, Masaryk University, Brno, Czech Republic
}

\section{SUMMARY}

Aims: Exposure of children to passive smoking is significantly associated with respiratory morbidity. Youngest children between 0-2 years are harmed in the most significant way, while, together with the growing age a decrease is observed of prevalence of respiratory diseases and influence of passive smoking.

Methods: During repeated investigations of children from European Longitudinal Study of Pregnancy and Childhood (ELSPAC) it was assessed, whether and how in the period from the birth to five years of age varied the rate of children exposed to environment filled with smoke and what were the differences in the frequency of diseases among the groups of children with different exposure level. Some selected characteristics of health were chosen from documentation provided in the 6th, 18th month and 5 years of children's age and processed in four children groups that differ in smoking behaviour of their mothers. The differences were statistically assessed in SPSS programme.

Results: In all compared age categories were children of smoking mothers more often exposed to stay in environment filled with smoke: children of middle and heavy smokers more, children of light smokers less. In all groups of smoking mothers, children were more often protected from exposure to passive smoking in the age of six months than after they reached 18 months and 5 years of age: differences were mostly statistically significant on the level of $1 \%$ of significance. Attending the kindergarten presents significant protecting factor for five years old children: they are more exposed during weekends than on week days $(p<0.001$, resp. $p<0.01)$. Both respiratory symptomatology and morbidity were highly significantly increased in previous life periods of those children, whose mothers smoked. At the age of five, life in smoking household causes more frequent incidence of asthmatic symptomatology: wheezing and apnoe, and higher prevalence of allergies against home and pollen dust with breathlessness and wheezing as well $(p<0.05)$.

Conclusions: ELSPAC study ascertained significant influence of maternal smoking on children's health in relation to passive smoking. Consequences of exposure clinically manifest themselves especially in increased incidence of respiratory and allergic morbidity.

Key words: passive smoking, children, respiratory morbidity, trends

Address for correspondence: L. Kukla, Department of Preventive and Social Pediatry, Faculty of Medicine, MU, Brno, Bieblova 16, 613 00 Brno, Czech Republic. E-mail: lubomir.kukla@tiscali.cz

\section{INTRODUCTION}

Exposure to passive smoking is a great and widespread problem. It is commonly accepted that children's exposure to tobacco smoke during fetal development and their exposure to environmental tobacco smoke (ETS) during childhood are most ubiquitous and hazardous factors within the whole children's environmental exposures. According to a report from the European Community Respiratory Health Survey (ECRHS, 1), which included data from almost 8,000 never-smoking adults from 36 cities in 16 countries, $65 \%$ had at least one smoking parent during childhood.

The effect of maternal smoking during pregnancy on children's birthweight has been recognized and described at 1957 (2) and ten years later the first report about the adverse effects of environmental tobacco smoke exposure was published (3). Since that time, several hundreds studies about relationship between ETS exposure and respiratory illness, their complications, the behavioral and neurocognitive damages have been published (4).
Children exposed to ETS have an increased risk of incidence of both upper and lower respiratory tract infections and symptoms, such as cough, phlegm production, otitis media, bronchitis, bronchiolitis and pneumonia, as well as wheeze and asthma (1). Higher incidence of respiratory syncytial virus bronchiolitis in infants is considered to be the major factor for the allergic responses, as these agens disrupt the process of the Th immunologic system physiological maturation (5).

An approximate doubling of the risk of lower respiratory tract infection in children exposed to ETS declines after the age of 2. These trends may be influenced by the fact that older children spend less time with their smoking parents (6).

Prospective European Longitudinal Study of Pregnancy and Childhood (ELSPAC) repeatedly evaluates relations between smoking of mothers and health status of their children. Investigation in six months showed that children of middle or heavy smokers were significantly more often repeatedly ill and hospitalized. Presence of heavy smokers (20 and more cigarettes a day) in this life period was rather rare. Increased incidence of health 
problems was represented mainly by acute diseases of both upper and lower respiratory tract, otitis media, gastrointestinal problems (diarrhoea, emesis) and especially by incidence of asthmatic symptomatology (wheezing, gasping) (7).

Also subsequent investigation of children aged 18 months produced similar results. Criterion of the passive smoking influence was presented by data on usual duration of children's exposure to smoke. Also in this age both infectious diseases of respiratory tract and gastrointestinal and asthmatic symptoms occurred more often in children exposed to environmental smoke. The lenght of exposure was in positive association with prevalence of illness in children (8).

Verification of prevalence of different diseases in children from ELSPAC study was repeated when they were five years old. We assessed whether and how the rate of children exposed to cigarette smoke changed and what were differences in disease frequency in children's groups with different exposure.

\section{METHODS}

Questionnaires were filled in for 3,554 5-year-old children, mothers gave also information about their smoking behaviour according to which the children were divided into four groups:

- non-smoking mother (NS)

- mothers are light smokers, they smoke daily up to 10 cigarettes (S1)

- mothers are middle smokers, they smoke daily 11 to 19 cigarettes (S2)

- mothers are heavy smokers, they smoke daily 20 and more cigarettes (S3).

Questionnaires also attempted to find how many smokers live in household, how many cigarettes smoke fathers of children. Mothers guessed how many hours a day in average children spend in environment filled with cigarette smoke separately during the weekends and week days.

Data about health status of children during the last two years (from the last investigations) were obtained from mothers and physicians. They contained these characteristics:

- overall evaluation of child's health status,

- hospitalization, curative stays in spa, therapeutic and preventive medical care, special investigations, operations, injuries

- symptoms of respiratory diseases

- symptoms of gastrointestinal diseases

- allergies

- symptoms of difficulties of sensory organs

- motoric and speech disorders

Some selected health characteristics were chosen also from documentation provided in the 6th and 18th month of age and processed for four children groups that differ in smoking behaviour of their mothers.

Differences were statistically evaluated by SPSS programme (Pearson's $\chi^{2}$ and Fisher test, probability rate, linear associations, ANOVA). The observed/expected ratio $(\mathrm{O} / \mathrm{E})$ was calculated as:

(NpNS : NpS1/S2,S3) x (NcS1/S2,S3 : NcNS), where $\mathrm{Np}=$ number of persons in NS, S1, S2, S3 groups $\mathrm{Nc}=$ number of cases in NS, S1, S2, S3 groups

\section{RESULTS}

Group of children, whose mothers do not smoke, consisted of 2,692 children ( $75.7 \%$ of all). Group of children with mothers who smoked lightly consisted of 477 children (13.4\%), 322 chidren had mothers who were middle smokers $(9.1 \%)$ and 63 children were born to heavy smoking mothers $(1.8 \%)$.

From 862 smoking mothers there were 55.3\% light, 37.4\% middle and $7.3 \%$ heavy smokers.

While only $8 \%$ women from the whole set smoked after the delivery, the prevalence of smokers has increased already during the first six months after the birth of child to cca $24 \%$ and kept this level during whole infant, toddler and preschool ages in observed children (Table 1). The rate of middle and heavy smokers has increased. As during the stay in maternity hospital and the first half year after the birth contact of these children with heavy smokers was rather rare, was this group for the purpose of evaluation added to the group of children born to middle smokers.

Table 1. Mothers' smoking habit in different periods of ELSPAC measurements (\% of children)

\begin{tabular}{|l|l|l|l|}
\hline Age of children & $\begin{array}{l}\text { After } \\
\text { delivery }\end{array}$ & $\mathbf{6}$ months & $\mathbf{5}$ years \\
\hline Non-smoking mother (NS) & 91.8 & 76.2 & 75.7 \\
\hline $\begin{array}{l}\text { Light smoker } \\
\text { (S1, } \leq 10 \text { cig/day) }\end{array}$ & 7.1 & 16.8 & 13.4 \\
\hline $\begin{array}{l}\text { Middle smoker } \\
\text { (S2, 11-20 cig/day) }\end{array}$ & 0.9 & 7.0 & 9.1 \\
\hline $\begin{array}{l}\text { Heavy smoker } \\
\text { (S3, > 20 cig/day) }\end{array}$ & 0.2 & 0.0 & 1.8 \\
\hline
\end{tabular}

Smoking habits of mothers were associated with smoking profile of the whole family: non-smoking women had most often also non-smoking partners, and/or other family members, which means that $71.1 \%$ children from the whole set lived in non-smoking family. Paradoxically, also 5.9\% of light and 3.5\% middle smokers presented their families as non-smoking: they probably wanted to express that neither they nor anyone else smoke at home. Only in one quarter of those children, whose mothers do not smoke, is one smoker in family. In case of one third of children from other groups only mothers smoke. Most of children, whose mothers smoke, lived in family with other smokers. Smoking intensity of mothers is directly associated with smoking intensity of their partners (Table 2).

Smoking habit of mothers influences exposures of children to passive smoking within home environment: while most of children of non-smoking mothers and app. two thirds of children of light smokers are not passive smokers, only one third of children who were born to middle and about $15 \%$ of those born to heavy smokers are not in danger. In both compared age cathegories, children of smoking mothers were more often exposed to ETS with children of middle and heavy smokers exposed more freqeuently than children of light smokers and non-smokers. When children were really small (about six months), they were somewhat more often protected from exposure to passive smoking than in time when they reached 5 years. This was true for all groups of smo- 
Table 2. Smoking in families of 5-year-old children (\%)

\begin{tabular}{|l|l|l|l|l|}
\hline $\begin{array}{l}\text { Number of smokers at homel } \\
\text { mothers'smoking }\end{array}$ & NS & S1 & S2 & S3 \\
\hline $\begin{array}{l}\text { Number of children } \\
\text { in the group }\end{array}$ & 2,692 & 477 & 322 & 63 \\
\hline None & 71.1 & 5.9 & 3.5 & 0.0 \\
\hline One & 26.1 & 34.0 & 32.2 & 30.2 \\
\hline Two & 2.1 & 52.9 & 56.8 & 61.9 \\
\hline Three & 0.4 & 5.2 & 6.3 & 7.9 \\
\hline Four and more & 0.2 & 2.0 & 1.2 & 0.0 \\
\hline An average & $0.33^{\star \star \star}$ & 1.63 & 1.70 & 1.78 \\
\hline $95 \% \mathrm{Cl}$ & $0.1-0.6$ & $0.8-2.2$ & $1.0-2.4$ & $0.9-2.5$ \\
\hline $\begin{array}{l}\text { Number of cigarettes smoked } \\
\text { daily by husband in average }\end{array}$ & $3.69^{\star \star *}$ & 8.50 & 12.29 & 18.94 \\
\hline $95 \% \mathrm{Cl}$ & $0.4-3.8$ & $4.0-9.7$ & $4.9-18.9$ & $5.5-27.5$ \\
\hline
\end{tabular}

Statistic significance: ${ }^{* *}=p<0.001$

Note.: NS = non-smokers, S1 = light smokers, S2 = middle smokers, S3 = heavy smokers

king mothers: differences were statistically significant, in most of cases on $1 \%$ level of significance (Table 3 ).

In five years old children, the time of exposure to passive smoking between weekend and week days was distinguished. In most of cases children are more exposed to passive smoking

Table 3. Children's exposure to ETS at homes (\%)

\begin{tabular}{|c|c|c|c|c|}
\hline & NS & S1 & S2 & S3 \\
\hline \multicolumn{5}{|l|}{ At the age of 6 months exposed } \\
\hline Whole day & 0.2 & 0.1 & 0.7 & \\
\hline$\geq 5$ hours & 0.1 & 0.3 & $2.3^{*}$ & \\
\hline$<5$ hours & 6.1 & $13.6^{*}$ & $43.1^{\star \star \star}$ & \\
\hline No exposure & 93.6 & $86.0^{*}$ & $53.9^{\star \star \star}$ & \\
\hline $\begin{array}{l}\text { No. of children at the age } \\
\text { of } 6 \text { months }\end{array}$ & 3,263 & 252 & 39 & 0 \\
\hline \multicolumn{5}{|l|}{ At the age of 5 years exposed } \\
\hline \multicolumn{5}{|l|}{ Working day } \\
\hline Whole day & 0.3 & 0.4 & 0.9 & 1.6 \\
\hline More than 5 hours & 0.4 & 1.1 & $4.1^{*}$ & $7.9^{*}$ \\
\hline 3 to 5 hours & 0.8 & 1.9 & $10.3^{* *}$ & $22.2^{\star \star}$ \\
\hline 1 to 3 hours & 1.6 & $5.8^{*}$ & $16.3^{\star \star}$ & $27.0^{\star \star}$ \\
\hline Less than 1 hour & 5.2 & $18.9^{*}$ & $28.5^{\star \star}$ & $23.8^{\star}$ \\
\hline No exposure & 91.8 & $71.8^{\star}$ & $39.8^{\star *}$ & $17.5^{\star \star \star}$ \\
\hline \multicolumn{5}{|l|}{ Weekend } \\
\hline Whole day & 0.7 & 0.9 & $2.2^{*}$ & $4.8^{\star \star}$ \\
\hline More than 5 hours & 0.6 & 0.4 & $7.8^{\star \star}$ & $14.3^{\star *}$ \\
\hline 3 to 5 hours & 1.0 & 3.2 & $9.7^{* \star}$ & $19.0^{* *}$ \\
\hline 1 to 3 hours & 3.3 & $7.3^{*}$ & $15.3^{\star *}$ & $23.8^{\star \star}$ \\
\hline Less than 1 hour & 9.6 & $25.8^{*}$ & $28.8^{* *}$ & $22.2^{*}$ \\
\hline No exposure & 84.8 & $62.4^{*}$ & $36.3^{* *}$ & $15.9^{\star \star \star}$ \\
\hline No. of children at the age of 5 years & 2,692 & 477 & 322 & 63 \\
\hline
\end{tabular}

Statistic significance: ${ }^{*}=p<0.05,{ }^{* *}=p<0.01,{ }^{* * *}=p<0.001$

Note: As only few mothers reported heavy smoking after delivery, the group S3 was added to the group S2 at the age of 6 months at weekends than during the week days, in group of non- and light smokers the differences in numbers of exposed children on different week days are statistically significant $(\mathrm{p}<0.001$ and $\mathrm{p}<0.01$, resp.) (Fig $1 \mathrm{a}-\mathrm{d})$.

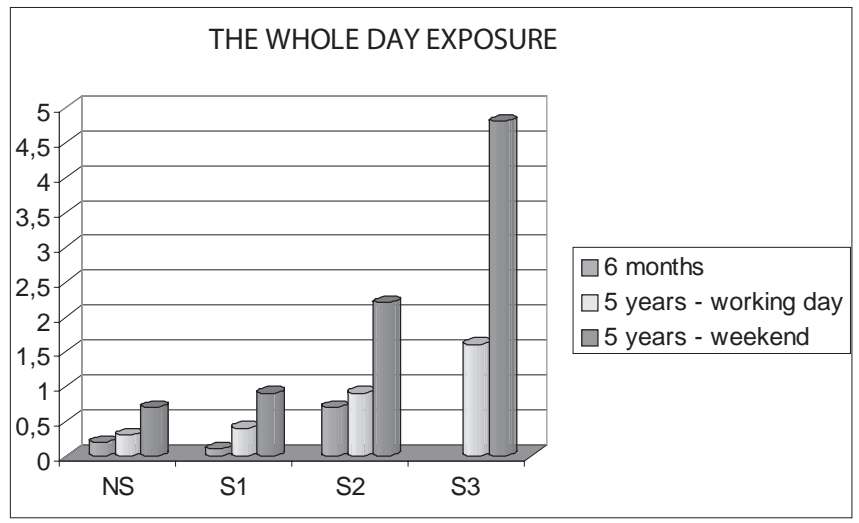

Fig. 1 a): Overview of ETS exposure of children (in \%) born to non-smoking (NS) and smoking (S1 = 1-10 cig/day, S2 = 11 - $20 \mathrm{cig} /$ day, S3 = more than $20 \mathrm{cig} /$ day) mothers at different children's age (6 months, 5 years).

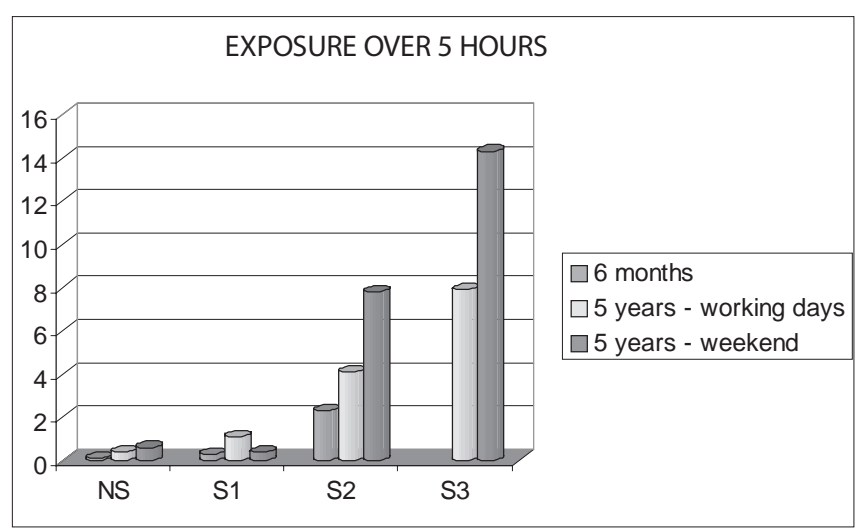

Fig. 1 b): Overview of ETS exposure of children (in \%) born to non-smoking (NS) and smoking (S1 = 1-10 cig/day, S2 = 11 - $20 \mathrm{cig} /$ day, S3 = more than $20 \mathrm{cig} /$ day) mothers at different children's age (6 months, 5 years).

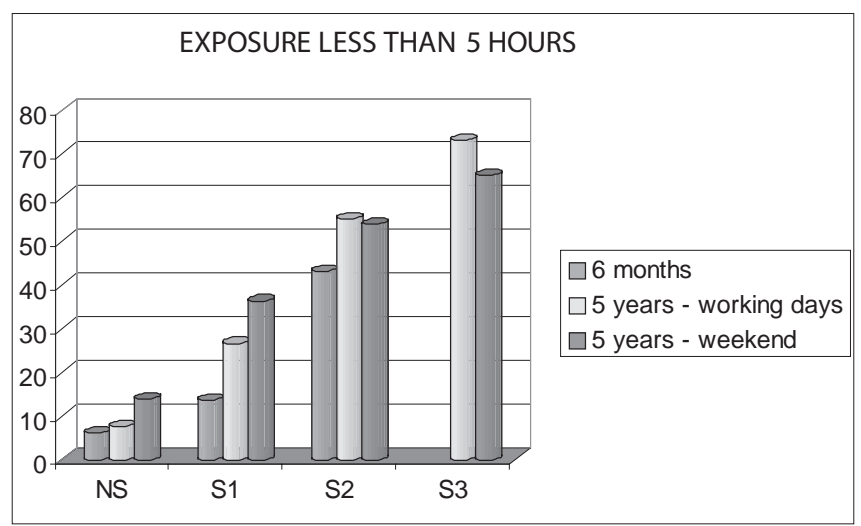

Fig. 1 c): Overview of ETS exposure of children (in \%) born to non-smoking (NS) and smoking (S1 = 1-10 cig/day, S2 = 11 - 20 cig/day, S3 = more than 20 cig/day) mothers at different children's age (6 months, 5 years). 


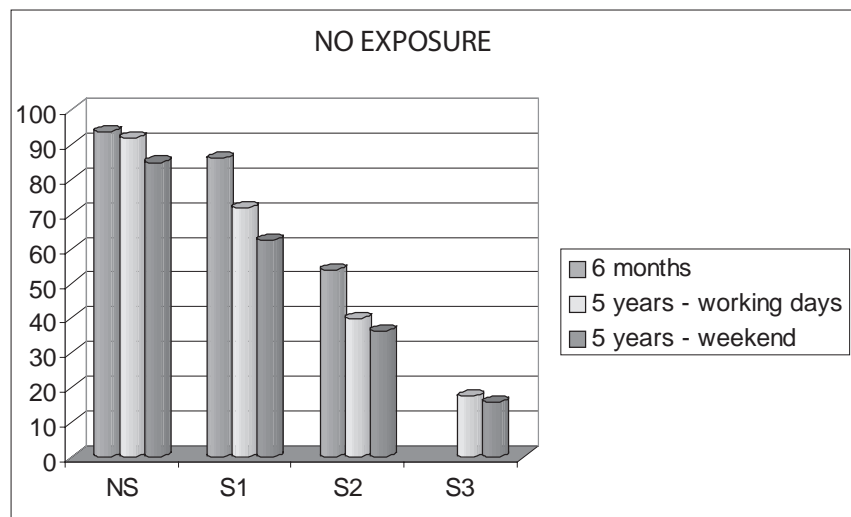

Fig. 1 d): Overview of ETS exposure of children (in \%) born to non-smoking (NS) and smoking (S1 = 1-10 cig/day, S2 = 11 - 20 cig/day, S3 = more than 20 cig/day) mothers at different children's age (6 months, 5 years).
Incidence rate of various observed symptoms and diseases, which are given in methodology, was - with rare exceptions - similar in all four groups in five years old children, also in the area of respiratory symptomatology and morbidity. Morbidity was highly significantly increased in previous life periods of those children, whose mothers smoked (Table 4). Higher rate of incidence of asthmatic symptomatology (wheezing and also quite alarming incidence of apnoe) observed twice to three times more often in children of middle, resp. heavy smokers $(p<0.05)$ is, on the other hand, the only factor of all factors observed that is influenced by ETS polluted environment of preschool age children. In these two groups, there were also more children with allergy to home and pollen dust and their allergies also more often manifest themselves by wheezing and breathlessness $(\mathrm{p}<0.05)$.

During all investigation periods there were no differences observed among children belonging to various groups according to the smoking behaviour of mothers in respect of preventive health care required, as shown by the number of preventive check-ups

Table 4. Health problems of children whose mothers have different smoking habit (the observed/ expected ratio O/E) at children's different periods of age (6 months, 18 months, 5 years)

\begin{tabular}{|c|c|c|c|c|c|}
\hline Marker of health status & Age & NS & S1 & S2 & S3 \\
\hline \multirow[t]{3}{*}{ Cold } & $6 \mathrm{~m}$ & 1 & $1.30^{\star \star \star}$ & $1.20^{* *}$ & \\
\hline & $18 \mathrm{~m}$ & 1 & $1.07^{\star}$ & $1.12^{\star \star}$ & \\
\hline & $5 y$ & 1 & 1.10 & 1.12 & 1.13 \\
\hline \multirow[t]{3}{*}{ Cough } & $6 \mathrm{~m}$ & 1 & $1.24^{\star \star \star}$ & $1.27 * \star \star$ & \\
\hline & $18 \mathrm{~m}$ & 1 & $1.10^{*}$ & $2.82^{\star \star \star}$ & \\
\hline & $5 y$ & 1 & 1.01 & 1.00 & 0.89 \\
\hline \multirow[t]{3}{*}{ Several days period of cough } & $6 \mathrm{~m}$ & 1 & $1.25^{\star \star}$ & $1.33^{* \star *}$ & \\
\hline & $18 \mathrm{~m}$ & 1 & $1.10^{*}$ & $1.11^{*}$ & \\
\hline & $5 y$ & 1 & 1.00 & 0.98 & 0.98 \\
\hline \multirow[t]{3}{*}{ Wheezing } & $6 \mathrm{~m}$ & 1 & $1.41^{\star \star}$ & $1.51^{\star \star}$ & \\
\hline & $18 \mathrm{~m}$ & 1 & $1.33^{\star}$ & $1.41^{*}$ & \\
\hline & $5 y$ & 1 & 1.07 & 1.16 & 1.13 \\
\hline \multirow[t]{3}{*}{ Several days period of wheezing } & $6 \mathrm{~m}$ & \multicolumn{4}{|c|}{ Not measured } \\
\hline & $18 \mathrm{~m}$ & 1 & $1.26^{\star}$ & $1.22^{*}$ & \\
\hline & $5 y$ & 1 & $1.21^{*}$ & $1.34^{*}$ & $1.36^{\star}$ \\
\hline \multirow[t]{3}{*}{ Breathless } & $6 \mathrm{~m}$ & 1 & 0.98 & $1.54^{*}$ & \\
\hline & $18 \mathrm{~m}$ & 1 & 0.69 & $1.64^{*}$ & \\
\hline & $5 y$ & 1 & 0.81 & 1.18 & 0.48 \\
\hline \multirow[t]{3}{*}{ Bronchiolitis, pneumonia } & $6 \mathrm{~m}$ & \multicolumn{4}{|c|}{ Not measured } \\
\hline & $18 \mathrm{~m}$ & 1 & 1.03 & $1.12^{* *}$ & \\
\hline & $5 y$ & 1 & 0.90 & 0.96 & 0.80 \\
\hline \multirow[t]{3}{*}{ Otitis media } & $6 \mathrm{~m}$ & 1 & $1.37^{*}$ & $1.78^{\star \star \star}$ & \\
\hline & $18 \mathrm{~m}$ & 1 & 1.09 & $1.84^{\star \star}$ & \\
\hline & $5 y$ & 1 & 0.91 & 0.86 & 0.73 \\
\hline \multirow[t]{3}{*}{ Hospitalization } & $6 \mathrm{~m}$ & 1 & $1.32^{\star \star}$ & $1.84^{\star \star \star}$ & \\
\hline & $18 \mathrm{~m}$ & 1 & 1.10 & $1.27^{*}$ & \\
\hline & $5 y$ & 1 & 1.02 & $1.11^{*}$ & 0.69 \\
\hline \multirow[t]{3}{*}{ Number of children } & $6 \mathrm{~m}$ & 3,263 & 252 & 39 & 0 \\
\hline & $18 \mathrm{~m}$ & 2,708 & 597 & 249 & 0 \\
\hline & $5 y$ & 2,692 & 477 & 322 & 63 \\
\hline
\end{tabular}

Statistic significance: ${ }^{*}=p<0.05,{ }^{* *}=p<0.01,{ }^{* * *}=p<0.001$

Note: As only few mothers reported heavy smoking after delivery, the group S3 was added to the group S2 at the age 6 months 
Table 5. Needs of the health care (an average number of contacts with a physician)

\begin{tabular}{|l|l|l|l|l|l|}
\hline Type of the care & & NS & S1 & S2 & S3 \\
\hline Preventive care: & & & & & \\
\hline Age 18 months & Average & 4.5 & 4.4 & 4.5 & \\
\hline & $95 \% \mathrm{Cl}$ & $2.8-6.1$ & $2.6-5.9$ & $2.7-6.3$ & \\
\hline Age 5 years & Average & 1.7 & 1.8 & 1.8 & 1.9 \\
\hline & $95 \% \mathrm{Cl}$ & $0.5-2.1$ & $0.5-2.3$ & $0.9-2.7$ & $0.7-2.7$ \\
\hline Curative care: & & & & & \\
\hline Age 18 months & Average & 5.8 & 6.1 & 6.2 & \\
\hline & $95 \% \mathrm{Cl}$ & $4.5-6.0$ & $3.8-6.4$ & $4.7-6.9$ & \\
\hline Age 5 years & Average & 17.4 & 17.9 & $20.1^{* *}$ & 14.5 \\
\hline & $95 \% \mathrm{Cl}$ & $15.3-18.5$ & $16.1-19.3$ & $19.5-29.8$ & $12.7-17.5$ \\
\hline $\begin{array}{l}\text { Specialists' } \\
\text { consulting }\end{array}$ & & & & & \\
\hline Age 18 months & Average & 1.0 & 0.9 & 1.2 & \\
\hline & $95 \% \mathrm{Cl}$ & $0.1-1.8$ & $0.1-1.8$ & $0.2-2.0$ & \\
\hline Age 5 years & Average & 2.0 & 1.9 & 1.9 & 1.3 \\
\hline & $95 \% \mathrm{Cl}$ & $0.4-2.9$ & $0.6-2.9$ & $0.8-2.4$ & $0.6-1.9$ \\
\hline
\end{tabular}

Statistic significance: ${ }^{* *}=p<0.01$

documented. Requirements for curative care and special consultations were higher in children of smoking mothers, the differences were not, however, significant (Table 5). On the other hand, children, whose mothers smoked, were significantly more often hospitalized in all observed investigation periods (Table 4).

\section{DISCUSSION}

Many studies have described, that the risk of respiratory morbidity is greatest in younger ages $(9,10,11)$. Unfortunatelly, the level of attributive risk of prenatal and postnatal exposure is not yet clearly known, i. e. whether it is more harmful for a child whose mother smokes during entire pregnancy or picks up smoking again after delivery.

Foetal development seems to be very important critical period of pulmonary vulnerability and several studies have confirmed the clear associations between prenatal exposure to maternal smoking and decreasing of pulmonary functions in newborns $(12,13)$. The effect of ETS exposure on the incidence of pneumonia and bronchiolitis seems to be the highest during the first year of life $(10,14)$, alike the necessity of hospitalization for respiratory illness at the same age (15). On the other hand, the cough in relation to parental smoking was described as declining after age 13 (16). The epidemiologic data regarding possible link between ETS and otitis media has been reviewed several times with the clear conclussion that there is likely to be a causal relationship between parental smoking and both acute and chronic middle ear disease in children, particularly under 2 years of age (17).

As it is not known why the adverse respiratory consequences of parental smoking decline with the children's age, there are hypotheses, that older children spend less time in the presence of smoking parents $(6,18,19)$.
On the other hand, the trends of development of asthmatic respiratory symptoms associated with foetal / infants exposure to passive smoking do not show similar age-related declination. Maternal smoking was described in relation to increased incidence of wheezing illness up to 6 years of age (20). Wheeze in childhood has been found to be related to postnatal exposure even after adjusting for the effect of prenatal exposure (21). The influence of prenatal and postnatal exposure to smoking carries a substantial risk for developing asthma and respiratory symptoms even in adulthood: in recent Norwegian study the adjusted attributable fractions of the adult incidence of asthma were in $17.3 \%$ caused by maternal smoking and in $9.3 \%$ by smoking of other household members (22).

The latest hypothesis is that the postnatal exposure to ETS operates as a trigger of wheezing attacks rather than as a factor inducing asthma, whereas in utero exposure it may increase the risk of developing asthma (1). The evidence regarding ETS and asthma is so strong that several authors support the causal relationship. The strong support for the hypothesis that the associations are not attributable to unmeasured confounders is in reports that asthma severity has improved in children when their exposure was reduced (4).

Mechanisms by which maternal smoking during pregnancy and children's exposure to ETS might cause respiratory illnesses include the decreased mucociliary clearance and opening the respiratory ways to entry of microbes impairing immune system functions, hyperplasia of adenoids (23). To the higher risk of asthma among children exposed to ETS contribute many chemicals with their irritant effects, bronchial hyperresponsiveness to allergens, impairment of the pulmonal elasticity, decreased pulmonary functions and alterations in their circadian variations $(12,24,25,26)$. After birth, the changes in adaptive immune competence involve the decrease of $\mathrm{Th}_{2}$ dominance and acquisition of $\mathrm{Th}_{1}$ under physiological conditions. In contrast, the delay in these maturation changes and persistence of foetal $\mathrm{Th}_{1} / \mathrm{Th}{ }_{2}$ paradigm provides an explanation for the susceptibility to severe viral infections and consequent allergic sensitization in early infancy (5).

In ELSPAC study we could confirm that frequency of most respiratory diseases caused by acute infections of both upper and lower respiratory tract with otitis media complications decreased together with growing age and was no longer associated with exposition of children to passive smoking. On the other hand, as it was observed, incidence of asthmatic symptomatology (wheezing) associated with smoking behaviour of mothers increased together with chidren's growing age.

Results of our prospective observation verify previous findings in similar foreign studies, which identically describe higher acute respiratory morbidity in younger age cathegories of exposed children ( 0 to 2 years), than in their higher age (preschool and young school age) (6). We could also verify conclusions of US EPA (27) that influence of passive smoking in older children more distinctly manifest itself in form of symptomatology pointing to airways obstruction.

On the other hand we did not prove, that children in older age are less often exposed to environment filled with harmful substances from cigarette smoke. In the set of mothers from ELSPAC study, more than $41 \%$ women stated during the first investigation (in the 18th-20th week of pregnancy) smoking behaviour in 
their personal history, $23 \%$ of women smoked 9 months before pregnancy. After pregnancy verification most of smokers gave up smoking, only cca $7 \%$ of mothers smoked during the whole pregnancy. The same prevalence of smokers was found during investigation in six weeks after the birth (28). Shortly after that many women returned again to this autoaggressive behaviour and in 18 months after delivery almost one fourth of mothers smoked again and this frequency did not significantly change in further period. Unfortunatelly, many women increased step by step their everyday cigarette consumption, so the rate of middle and especially heavy smokers among smoking women as a whole significantly increased. We do not suppose some serious errors in the self-reported mothers' smoking habit; another study from the same region showed very similar prevalence of smokers during pregnancy verified by urinary cotinine levels (29).

During the 5-years follow-up period, women also decreased their effort not to smoke in rooms where a child stays and to protect it at least partly from influence of harmful substances. Insensible behaviour of smokers towards their children was evident especially by data collected during 5 years of investigation. We found out that during weekends compared to week days the load for a child increased, because most of children attend some preschool facility. Parents are unable to stop smoking at home despite of significantly more frequent occurrence of respiratory diseases in comparison with non-smoking families.

\section{CONCLUSIONS}

ELSPAC study verified influence of exposure of children to ETS on their respiratory morbidity, which developed after the birth to 5 years in similar way as it was proved in other foreign studies: prevalence of diseases of both upper and lower respiratory tract and cough decreased together with age; higher incidence of wheezing remained especially in children of heavy smokers also in the fifth year of their life. According to the data given by parents, older children were not less exposed to passive smoking, trends were rather opposite. Protection of children from the exposure to ETS is priority task of physicians and whole society.

\section{Acknowledgements}

Study was supported by grant IGA MH CR no. NR 8380-3/2005.

\section{REFERENCES}

1. Janson C. The effect of passive smoking on respiratory health in children and adults. Int J Tuberc Lung Dis. 2004;8(5):510-6.

2. Simpson WJ. A preliminary report on cigarette smoking and the incidence of prematurity. Am J Obstet Gynecol. 1957;73(4):808-15.

3. Cameron P. The presence of pets and smoking as correlates of perceived disease. J Allergy. 1967;40(1):12-5

4. DiFranza JR, Aligne AC, Weitzman M. Prenatal and postnatal environmental tobacco smoke exposure and children's health. Pediatrics. 2004;113(4 Suppl):1007-15

5. Bellanti JA, Malka-Rais J, Castro HJ, De Innocencio JM, Sabra A Developmental immunology: clinical application to allergy- immunology. Ann Allergy Asthma Immunol. 2003;90(6 Suppl 3):2-6.

6. Li JS, Peat JK, Xuan W, Berry G. Meta-analysis on the association between environmental tobacco smoke (ETS) exposure and the prevalence of lower respiratory tract infection in early childhood. Pediatr Pulmonol. 1999;27(1):5-13.
7. Kukla L, Hrubá D, Tyrlík M. Smoking of mothers after the delivery significantly contributes to increased newborn and infant morbidity. Čes-slov Pediat. 2004;59(5):225-8. (In Czech.)

8. Kukla L, Hrubá D, Tyrlík M. Influence of exposition to passive smoking after the birth on the health status of children in infant and toddler age. Čes-slov Pediat. 2005;60(2):62-9. (In Czech.)

9. Cook DG, Strachan DP. Health effects of passive smoking: 3. parental smoking and prevalence of respiratory symptoms and asthma in school age children. Thorax. 1997;52(12):1081-94.

10. Fergusson DM, Horwood LJ. Parental smoking and respiratory illness during early childhood: a six year longitudinal study. Pediatr Pulmonol. 1985;1(2):99-106.

11. Gergen PJ, Fowler JA, Maurer KR, Davis WW, Overpeck MD. The burden of environmental tobacco smoke exposure on the respiratory health of children 2 months through 5 years of age in the United States: Third National Health and Nutrition Examination Survey, 1988 to 1994. Pediatrics. 1998;101(2):118-25.

12. Stick SM, Burton PR, Gurrin L, Sly PD, LeSouef PN. Effects of maternal smoking during pregnancy and a family history of asthma on respiratory function in newborn infants. Lancet. 1996;348(9034):1060-4.

13. Hanrahan JP, Tager IB, Segal MR, Tosteson TD, Castile RG, Van Vunakis $\mathrm{H}$, et al. The effect of maternal smoking during pregnancy on early infant lung function. Am Rev Respir Dis. 1992;145(5):1129-35.

14. Rylander E, Peshagen C, Ericksson M, Bermann, G. Parental smoking, urinary cotinine, and wheezing bronchitis in children. Epidemiology. 1995;6(3):289-93.

15. Chen Y, Li WX, Yu SZ, Qian WH. Chang-Ning epidemiological study of children's health: I: Passive smoking and children's respiratory diseases. Int J Epidemiol. 1988;17(2):348-55.

16. Charlton A. Children's coughs related to parental smoking. Br Med J (Clin Res Ed). 1984 Jun 2;288(6431):1647-9.

17. Strachan DP, Cook DG. Health effects of passive smoking: 4: Parental smoking, middle ear disease, and adenotonsilectomy in children. Thorax. 1998;53(1):50-6.

18. Kohler E. Sollich V, Schuster R, Thal W. Passive smoke exposure in infants and children with respiratory tract diseases. Hum Exp Toxicol. 1999; 18(4):212-7.

19. Duff AL, Pomeranz ES, Gelber LE, Price GW, Farris H, Hayden FG, et al. Risk factors for acute wheezing in infants and children: viruses, passive smoke, and IgE antibodies to inhalant allergens. Pediatrics. 1993 Oct;92(4):535-40.

20. Strachan, DP, Cook DG. Health effects of passive smoking: 6: Parental smoking and childhood asthma: longitudinal and case-control studies. Thorax. 1998;53(3):204-12.

21. Lux AL, Henderson AJ, Pollock SJ; ALSPAC Study Team. Wheeze associated with prenatal tobacco smoke exposure: a prospective, longitudinal study. Arch Dis Child. 2000;83(3):307-12.

22. Skorge TD, Eagan TML, Eide GE, Gulsvik A, Bakke PS. The adult incidence of asthma and respiratory symptoms by passive smoking in utero or in childhood. Am J Respir Crit Care Med. 2005;172(1):61-6.

23. National Cancer Institute. Health effects of exposure to environmental tobacco smoke. The Report of California Environmental Protection Agency. Smoking and Tobacco Control Monograph, No 10. Bethesda: NCI; 1999.

24. Neddenriep D, Marinez FD, Morgan, WJ. Increased specific lung compliance in newborns whose mothers smoked during pregnancy. Am Rev Respir Dis. 1990;141:282-7.

25. Cook DG, Strachan DP. Health effects of passive smoking: 7: Parental smoking, bronchial reactivity, and peak flow variability in children. Thorax. 1998;53(4):295-301

26. Agabiti N, Mallone S, Forastiere F, Corbo GM, Ferro S, Renzoni E, et al The impact of parental smoking on asthma and wheezing. Epidemiology. 1999;10(6):692-8.

27. Respiratory health effect of passive smoking: lung cancer and other disorders. EPA/600/6-90/006F. Washington DC: U.S. Environmental Protection Agency; 1992.

28. Kukla L, Hrubá D, Tyrlík M. Changes of smoking behaviour of women in pregnancy. Results of ELSPAC study. Prakt Lék. 1999;79(9):517-20. (In Czech.)

29. Hrubá D, Kachlík P: Influence of maternal active and passive smoking during pregnancy on birthweight in newborns. Cent Eur J Publ Health. 2000;8(4):249-52. 